\title{
Attitudes about and practices for skin cancer prevention among patients with dermatological issues in Hanoi, Vietnam: a cross-sectional study
}

Trang H. T. Nguyen", Bach X. Tran ${ }^{2,3 *}$, Sau H. Nguyen ${ }^{4,5}$, Carl A. Latkin ${ }^{3}$, Cuong T. Nguyen ${ }^{6,7}$, Son H. Nguyen ${ }^{8}$, Hai Q. Pham ${ }^{6,7}$, Cyrus S. H. Ho ${ }^{9}$, Roger C. M. Ho ${ }^{10,11}$ and Jin-Kyoung Oh ${ }^{1 *}$ (D)

\begin{abstract}
Background: Raising awareness and educating people regarding practices for skin cancer or melanoma prevention are critical in the context of the adversely increasing effects of global climate change. This study aimed to explore the knowledge, attitudes, and practices regarding skin cancer prevention and to determine the associated factors to knowledge, attitudes, and practices among dermatological patients in Vietnam.

Methods: This cross-sectional study included 590 dermatological patients between 18 and 82 years of age, who received an examination or treatment from the National Hospital of Dermatology in Hanoi, Vietnam, from September to December 2018. The respondents' attitudes on skin cancer and cancer prevention were assessed via face-to-face interviews with a structured questionnaire conducted by trained interviewers.

Results: Of the 590 respondents, the majority of people had correct responses to the question regarding skin cancer knowledge. Among the total participants, 39.8\% thought that they were at risk of skin cancer, and 13.8\% believed their occupation increased their skin cancer risk. The majority of respondents used hats (94.9\%) and sunscreen skin coats (89.5\%) and went into the shade (86.3\%) when exposed to the sun. Women were less likely to be aware of their skin cancer risk but were more likely to practice prevention behaviors.

Conclusion: Our results show that dermatological patients have acceptable knowledge towards skin cancer prevention, but still need to change their behavior to prevent the risk of skin cancer. This study highlights the importance of education to raise awareness regarding skin cancer in order to promote practice prevention strategies for skin cancer in Vietnam.
\end{abstract}

Keywords: Skin cancer, Attitudes, Practices

\footnotetext{
*Correspondence: bach.ipmph@gmail.com; bach@jhu.edu; jkoh@ncc.re.kr

${ }^{2}$ Department of Health Economics, Institute for Preventive Medicine and

Public Health, Hanoi Medical University, Hanoi 100000, Vietnam

'Department of Cancer Control and Population Health, National Cancer

Center Graduate School of Cancer Science and Policy, Goyang, Republic of

Korea

Full list of author information is available at the end of the article
}

(c) The Author(s). 2020 Open Access This article is licensed under a Creative Commons Attribution 4.0 International License, which permits use, sharing, adaptation, distribution and reproduction in any medium or format, as long as you give appropriate credit to the original author(s) and the source, provide a link to the Creative Commons licence, and indicate if changes were made. The images or other third party material in this article are included in the article's Creative Commons licence, unless indicated otherwise in a credit line to the material. If material is not included in the article's Creative Commons licence and your intended use is not permitted by statutory regulation or exceeds the permitted use, you will need to obtain permission directly from the copyright holder. To view a copy of this licence, visit http://creativecommons.org/licenses/by/4.0/. The Creative Commons Public Domain Dedication waiver (http://creativecommons.org/publicdomain/zero/1.0/) applies to the data made available in this article, unless otherwise stated in a credit line to the data. 


\section{Background}

We are currently having to manage the effects of global climate change on our health, especially skin cancer, or melanoma, in which the impact is more complicated and unpredictable. Based on the report from the Global Cancer Statistic 2018, there were 300,000 new cases of melanoma globally in 2018 and it was the 15th most common cancer in men and women [1].

While the prevalence of melanoma is more common among Caucasians living in the USA and Australia, it is uncommon in Asian countries, including Vietnam [1]. Previous studies showed that the differences in the incidence rates of melanoma of the skin depended on population groups or race/ethnicity $[2,3]$. Among Asians and Africans, people who have darker skin have a lower risk of skin cancer due to the presence of melanin. Melanin can be understood as a barrier to the effects of both ultraviolet (UV) A and B [4]. Vietnam is located in Asia; it is reasonable for skin cancer to be uncommon in Vietnam even though it is located in a tropical area with strong UV radiation [4]. Moreover, many studies have indicated an increasing trend in the incidence of skin cancer in European countries [5, 6], while the rates tended to be stable in Asia [5]. In Vietnam, based on the estimate from the International Agency for Research on Cancer, in 2018, there were 157 new cases of melanoma, and the mortality rate associated with this type of cancer was quite low compared with that associated with the other types of cancer ( $0.09 \%$ of the total cancer deaths) [1]. However, the incidence of and mortality associated with malignant skin cancer in Vietnam have remained stable in recent years.

Among the various risk factors, studies have reported that $86 \%$ of melanoma cases are caused by being exposed to UV radiation from the sunlight $[7,8]$. The association between sun exposure and malignant melanoma is complicated due to the transition of the global climate as well as ozone depletion, which lead to an increase in the amount of UV [9].

Skin cancer is less common in Vietnam compared to that in other countries $[1,5,6]$; however, UV exposure is an avoidable risk factor, and skin cancer is one of the few preventable forms of cancer. Moreover, global climate change has impacted countries globally; thus, Vietnam, a tropical country, has experienced increasing UV radiation, in addition to its already prolonged and high heat sun exposure. Therefore, it is essential to raise awareness about skin cancer and the methods that can be employed to prevent it as a result of the long-term sun exposure in Vietnam.

The knowledge and awareness of skin cancer were well documented in other countries. However, there is a lack of studies on skin cancer awareness and practices in Vietnam. This study aimed to examine the awareness of and prevention practices for skin cancer among people with dermatological issues in Vietnam.

\section{Methods \\ Study setting and subjects}

A cross-sectional study was conducted at the National Hospital of Dermatology in Hanoi, Vietnam, from September to December 2018. This hospital is one of the top specialty hospitals in Vietnam and provides services for a large number of patients from Hanoi and the surrounding provinces every year. We used a convenience sampling technique to recruit participants who met the following eligibility criteria: (1) 18 years old and above, (2) received an examination or treatment from the National Hospital of Dermatology, (3) agreed to participate in the study, and (4) had a condition that they were willing to communicate with the study team about. Patients with severe illness during the recruitment process were excluded.

\section{Measurements and instruments}

We conducted a pilot study among 20 participants of different ages, genders, and occupations to examine the acceptability and reliability of the structured questionnaire. In this pilot, the participants were requested to answer a 30-min face-to-face questionnaire. Information about the respondents' socioeconomic characteristics was collected, including age, gender, education, marital status, occupation, living area, and monthly income. This information was then used to develop the complete questionnaire. The monthly household income of the respondents was divided into four groups, from lowest to highest. Information on the respondents' dermatological histories included their previous diagnosis and issues. Finally, we asked respondents whether they had a family history of skin cancer and where they obtained information regarding the disease.

To gauge the respondents' knowledge regarding skin cancer, we asked participants to report their perceptions regarding the following: (1) common levels of skin cancer in Vietnam, (2) whether skin cancer is benign or malignant, (3) the possibility of skin cancer leading to death, and (4) the effects of cloudy days on the risk of skin cancer. The primary outcomes of this study were the attitudes and practices regarding skin cancer risk and prevention. Patients reported their attitudes regarding skin cancer risk; they were asked if they consider the risk of skin cancer in their daily life and their occupation. Moreover, they were asked to report their selfassessed frequency of taking measures to protect their skin when going into the sun. In Vietnam, women prefer to use a sunscreen coat, which can cover their whole or upper part of the body for cosmetic purpose. We used Likert scales including five options from "Never" to 
"Always" to assess the respondents' practices; higher scores indicated more preferable outcomes.

\section{Statistical analysis}

We analyzed the data using STATA version 12 (Stata Corp. LP, College Station, USA). Chi-squared and Mann-Whitney tests were used for the descriptive analyses of clinical and demographic characteristics among respondents as well as the sources of skin cancer's information. To identify the factors associated with attitudes about and practices for skin cancer prevention, multivariate logistic and Tobit regression analyses were used.
We applied a forward stepwise selection strategy to eliminate non-significant factors; the significance threshold for the inclusion of variables in the multivariate analysis was a $p$ value less than 0.2 based on the loglikelihood ratio test. $p$ values $<0.05$ were considered statistically significant.

\section{Results}

Overall, 590 respondents were enrolled in the study; Table 1 describes the demographic characteristics of those enrolled. The mean age of the respondents was 35.5 years $(\mathrm{SD}=12.3)$. The majority of participants were

Table 1 Characteristics of the participants who visited a hospital with dermatological issues in Hanoi, Vietnam, 2018

\begin{tabular}{|c|c|c|c|c|c|c|c|}
\hline \multirow[t]{3}{*}{ Characteristics } & \multicolumn{6}{|c|}{ Thinking he/she has a risk of skin cancer } & \multirow[t]{3}{*}{$\boldsymbol{p}$ value } \\
\hline & \multicolumn{2}{|l|}{ No } & \multicolumn{2}{|l|}{ Yes } & \multicolumn{2}{|l|}{ Total } & \\
\hline & $n$ & $\%$ & $n$ & $\%$ & $n$ & $\%$ & \\
\hline \multicolumn{8}{|l|}{ Gender } \\
\hline Male & 144 & 41.6 & 164 & 70.1 & 308 & 53.1 & $<0.01$ \\
\hline Female & 202 & 58.4 & 70 & 29.9 & 272 & 46.9 & \\
\hline \multicolumn{8}{|l|}{ Education } \\
\hline Under high school & 54 & 15.3 & 11 & 4.7 & 65 & 11.1 & $<0.01$ \\
\hline High school & 75 & 21.2 & 23 & 9.8 & 98 & 16.7 & \\
\hline Vocational colleges & 59 & 16.7 & 23 & 9.8 & 82 & 13.9 & \\
\hline University/postgraduate & 166 & 46.9 & 177 & 75.6 & 343 & 58.3 & \\
\hline \multicolumn{8}{|l|}{ Marital status } \\
\hline Single/divorce/separation & 127 & 35.7 & 59 & 25.2 & 186 & 31.5 & 0.01 \\
\hline Living with a partner & 229 & 64.3 & 175 & 74.8 & 404 & 68.5 & \\
\hline \multicolumn{8}{|l|}{ Employment $^{a}$} \\
\hline Freelancer & 134 & 37.7 & 35 & 15 & 169 & 28.7 & $<0.01$ \\
\hline White collar & 88 & 24.8 & 148 & 63.2 & 236 & 40.1 & \\
\hline Blue collar & 50 & 14.1 & 18 & 7.7 & 68 & 11.5 & \\
\hline Student & 43 & 12.1 & 16 & 6.8 & 59 & 10.0 & \\
\hline Others & 40 & 11.3 & 17 & 7.3 & 57 & 9.7 & \\
\hline \multicolumn{8}{|l|}{ Living area } \\
\hline Urban & 216 & 60.8 & 92 & 39.3 & 308 & 52.3 & $<0.01$ \\
\hline Rural & 139 & 39.2 & 142 & 60.7 & 281 & 47.7 & \\
\hline \multicolumn{8}{|c|}{ Have family members with cancer } \\
\hline Yes & 11 & 3.1 & 10 & 4.3 & 21 & 3.6 & 0.46 \\
\hline No & 339 & 96.9 & 222 & 95.7 & 561 & 96.4 & \\
\hline \multicolumn{8}{|c|}{ Family income (Vietnamese thousands dong) ${ }^{\mathbf{b}}$} \\
\hline Lowest (0-10.000) & 140 & 41.08 & 54 & 24.43 & 194 & 35.53 & $<0.01$ \\
\hline Low (11.000-15.000) & 52 & 16.0 & 118 & 53.39 & 170 & 31.14 & \\
\hline High (16.000-20.000) & 62 & 19.08 & 26 & 11.76 & 88 & 16.12 & \\
\hline \multirow[t]{2}{*}{ Highest (23.000-40.000) } & 71 & 21.85 & 23 & 10.41 & 94 & 17.22 & \\
\hline & Mean & SD & Mean & SD & Mean & SD & $p$ value \\
\hline Age & 35.9 & 14 & 34.8 & 9.1 & 35.5 & 12.3 & 0.19 \\
\hline
\end{tabular}

${ }^{a}$ Employment: freelancer, people who are self-employed; white collar, office workers; blue collar, manual workers

${ }^{b}$ Family income: we calculated the mean monthly household income of each group 
males (53.1\%) and living in rural areas (52.3\%). Most of the respondents were white-collar workers (40.1\%), followed by freelancers (28.7\%).

Table 2 shows the clinical characteristics of the respondents. The most common diagnosis was atopic dermatitis (42.4\%), while the least common was autoimmune skin diseases (1.2\%). Only $6.0 \%$ of respondents had no dermatological diseases when they participated in the interview. Overall, $30.6 \%$ of respondents had more than one dermatological issue.

The knowledge, attitudes, and practices regarding skin cancer prevention by gender are demonstrated in Table 3. There was a similarity in the level of knowledge between males and females when answering the following true or false questions: "The risk of skin cancer decreases on cloudy days" (92.2\% of males and $88.6 \%$ of females responded correctly). "Skin cancer is not common in Vietnam" (72.5\% males and $65.1 \% \mathrm{fe}-$ males responded correctly). Regarding the attitude towards skin cancer, males were more concerned about their risk of skin cancer than females $(53.2 \%$ and $25.7 \%$, respectively). Besides, hat, umbrella, sunscreen coat, and going into the shade are the most common ways to prevent skin cancer in both sexes. However, female participants preferred to use sunscreen
(75.7\%), sunglasses (68.8\%), and sunscreen trousers (91.9\%) when compared to males $(13.0 \%, 33.8 \%$, and $43.5 \%$, respectively).

Table 4 presents the sources of skin cancer information among respondents. The most commonly used channel was the Internet (45.1\%), followed by the television $(22.5 \%)$ and social networks (22.0\%); $20.6 \%$ of respondents received information from health workers, and only $16.9 \%$ got information from friends or relatives.

Table 5 presents the factors associated with attitudes and practices regarding skin cancer risks and prevention. Female respondents were less likely to be aware of skin cancer risks (odds ratio $[\mathrm{OR}]=0.37 ; 95 \%$ confidence interval $[\mathrm{CI}]=0.23-0.59)$; however, they were more likely to practice prevention behaviors than men (Coef $=$ 5.88; $95 \% \mathrm{CI}=5.07-6.68)$. Compared to those who attained less than a high school degree, those who graduated from vocational colleges and university or postgraduate school were more likely to have more attention on the risk factors of skin cancer or a better attitude. Meanwhile, blue-collar workers were more likely to perceive that their occupation increases their skin cancer risk compared to freelance workers $(\mathrm{OR}=2.73$; $95 \% \mathrm{CI}=1.21-6.16)$. Finally, getting information about skin cancer from sources including mobile phones, the

Table 2 Clinical characteristics of the study participants who visited a hospital with dermatological issues in Hanoi, Vietnam, 2018

\begin{tabular}{|c|c|c|c|c|c|c|c|}
\hline \multirow[t]{3}{*}{ Characteristics } & \multicolumn{6}{|c|}{ Thinking he/she has a risk of skin cancer } & \multirow{3}{*}{$\begin{array}{l}\boldsymbol{p} \\
\text { value }\end{array}$} \\
\hline & \multicolumn{2}{|l|}{ No } & \multicolumn{2}{|l|}{ Yes } & \multicolumn{2}{|c|}{ Total } & \\
\hline & $n$ & $\%$ & $n$ & $\%$ & $n$ & $\%$ & \\
\hline \multicolumn{8}{|l|}{ Dermatology diagnosis } \\
\hline Atopic dermatitis & 99 & 28.3 & 148 & 63.8 & 247 & 42.4 & $<0.01$ \\
\hline Contact dermatitis & 77 & 22 & 29 & 12.5 & 106 & 18.2 & $<0.01$ \\
\hline Psoriasis & 26 & 7.4 & 4 & 1.7 & 30 & 5.2 & $<0.01$ \\
\hline Skin infection & 20 & 5.7 & 1 & 0.4 & 21 & 3.6 & $<0.01$ \\
\hline Tinea & 63 & 18 & 21 & 9.1 & 84 & 14.4 & $<0.01$ \\
\hline Autoimmune skin disease & 3 & 0.9 & 4 & 1.7 & 7 & 1.2 & 0.45 \\
\hline Urticaria & 49 & 14 & 31 & 13.4 & 80 & 13.7 & 0.83 \\
\hline Warts & 18 & 5.1 & 10 & 4.3 & 28 & 4.8 & 0.65 \\
\hline Zona & 32 & 9.1 & 13 & 5.6 & 45 & 7.7 & 0.12 \\
\hline Herpes simplex & 8 & 2.3 & 5 & 2.2 & 13 & 2.2 & 0.92 \\
\hline STDs & 8 & 2.3 & 5 & 2.2 & 13 & 2.2 & 0.92 \\
\hline Others & 81 & 23.1 & 36 & 15.5 & 117 & 20.1 & 0.03 \\
\hline \multicolumn{8}{|l|}{ Currently, have skin disease } \\
\hline No & 29 & 8.3 & 6 & 2.6 & 35 & 6.0 & 0.01 \\
\hline Yes & 321 & 91.7 & 226 & 97.4 & 547 & 94.0 & \\
\hline \multicolumn{8}{|c|}{ Have more than one dermatological disease } \\
\hline Healthy & 29 & 8.3 & 6 & 2.6 & 35 & 6.0 & $<0.01$ \\
\hline One disease & 203 & 58 & 166 & 71.6 & 369 & 63.4 & \\
\hline More than one disease & 118 & 33.7 & 60 & 25.9 & 178 & 30.6 & \\
\hline
\end{tabular}


Table 3 Knowledge, attitudes, and practices for skin cancer prevention among participants in Hanoi, Vietnam, 2018

\begin{tabular}{|c|c|c|c|c|}
\hline \multirow[t]{2}{*}{ Item } & \multicolumn{2}{|l|}{ Male } & \multicolumn{2}{|l|}{ Female } \\
\hline & $\overline{n=308}$ & $\%$ & $\boldsymbol{n}=272$ & $\%$ \\
\hline \multicolumn{5}{|l|}{ Knowledge on skin cancer } \\
\hline Skin cancer is not common in Vietnam & 241 & 78.2 & 177 & 65.1 \\
\hline Skin cancer is benign & 151 & 49.0 & 214 & 78.7 \\
\hline Skin cancer can be deadly & 89 & 28.9 & 114 & 41.9 \\
\hline The risk of skin cancer decreases in cloudy days & 284 & 92.2 & 241 & 88.6 \\
\hline \multicolumn{5}{|l|}{ Attitude about skin cancer } \\
\hline Thinking he/she has a risk of skin cancer & 164 & 53.2 & 70 & 25.7 \\
\hline Thinking his/her occupation increases skin cancer risk & 40 & 13.0 & 41 & 15.1 \\
\hline \multicolumn{5}{|l|}{ Prevention practice for skin cancer } \\
\hline Hat & 294 & 95.5 & 265 & 97.4 \\
\hline Umbrella & 227 & 73.7 & 227 & 83.5 \\
\hline Sunscreen coat & 258 & 83.8 & 266 & 97.8 \\
\hline Sunscreen trousers & 134 & 43.5 & 250 & 91.9 \\
\hline Sunglasses & 104 & 33.8 & 187 & 68.8 \\
\hline Sunscreen & 40 & 13.0 & 206 & 75.7 \\
\hline Go in the shade & 262 & 85.1 & 241 & 88.6 \\
\hline Take sunscreen pills & 9 & 2.9 & 17 & 6.3 \\
\hline
\end{tabular}

Internet, and social networks were positively associated with attitudes and practices regarding skin cancer.

\section{Discussion}

This current study found that participants who received examination or treatment from the National Hospital of Dermatology were concerned about their risk of melanoma. Respondents with higher education levels had more knowledge regarding skin cancer, and the respondents who were blue-collar workers were more concerned about their occupation increasing their risk of skin cancer.

Table 4 Sources of information on skin cancer among participants in Hanoi, Vietnam, 2018

\begin{tabular}{|c|c|c|c|c|c|c|c|}
\hline \multirow[t]{3}{*}{ Characteristics } & \multicolumn{6}{|c|}{ Thinking he/she has a risk of skin cancer } & \multirow{3}{*}{$\begin{array}{l}\boldsymbol{p} \\
\text { value }\end{array}$} \\
\hline & \multicolumn{2}{|l|}{ No } & \multicolumn{2}{|l|}{ Yes } & \multicolumn{2}{|c|}{ Total } & \\
\hline & $n$ & $\%$ & $n$ & $\%$ & $n$ & $\%$ & \\
\hline Friends/relatives & 78 & 22.2 & 21 & 8.9 & 99 & 16.9 & $<0.01$ \\
\hline Poster/banner & 48 & 13.7 & 28 & 11.9 & 76 & 13.0 & 0.53 \\
\hline Internet & 104 & 29.6 & 160 & 68.1 & 264 & 45.1 & $<0.01$ \\
\hline SMS/mobile phone & 53 & 15.1 & 24 & 10.2 & 77 & 13.1 & 0.09 \\
\hline Television & 94 & 26.8 & 38 & 16.2 & 132 & 22.5 & $<0.01$ \\
\hline Community leader & 52 & 14.8 & 29 & 12.3 & 81 & 13.8 & 0.40 \\
\hline Paper/book & 51 & 14.5 & 29 & 12.3 & 80 & 13.7 & 0.45 \\
\hline Health workers & 82 & 23.4 & 39 & 16.6 & 121 & 20.6 & 0.05 \\
\hline Social network & 82 & 23.4 & 47 & 20.0 & 129 & 22.0 & 0.34 \\
\hline Others & 43 & 12.2 & 15 & 6.4 & 58 & 9.9 & 0.02 \\
\hline
\end{tabular}

Our study reveals that the majority of participants had atopic dermatitis and that those diagnosed with atopic eczema were more likely to think that they have an increased risk of skin cancer compared to others. These results might be because these patients had many symptoms present on the skin surface, which lead them to be more concerned about their risk of skin cancer. A previous study on atopic eczema confirmed the increased risk of squamous cell carcinoma but not malignant melanoma among atopic dermatitis patients [10, 11].

It has been well documented that those from lower income groups are more vulnerable to an increased risk of occupational skin cancer as a result of their working environment [12]. This finding is in line with a previous report of a Peruvian cohort [13]. In a study conducted among medical students, it was found that the majority of the participants knew about the symptoms of and prevention behaviors for skin cancer [14]; this is likely explained by their high levels of education. Another study in America indicated that the majority of their respondents were more concerned about tanning to make them more attractive than the risk of skin cancer [15].

The risk factors for melanoma have been well documented in various studies. Previous studies conducted in the UK considered ozone depletion and climate change as risk factors that were increasing the incidence of melanoma [16, 17]. In these studies, the authors indicated that climate change was increasing the average temperature, which forces people to change their behaviors to have more outdoor activities, thus leading to 
Table 5 Factors associated with attitudes and practices for skin cancer prevention among participants in Hanoi, Vietnam, 2018

\begin{tabular}{|c|c|c|c|c|c|c|}
\hline \multirow[t]{2}{*}{ Characteristics } & \multicolumn{2}{|c|}{$\begin{array}{l}\text { Thinking he/she has a } \\
\text { risk of skin cancer }\end{array}$} & \multicolumn{2}{|c|}{$\begin{array}{l}\text { Thinking his/her occupation } \\
\text { increases skin cancer risk }\end{array}$} & \multicolumn{2}{|c|}{$\begin{array}{l}\text { Prevention for skin } \\
\text { cancer }\end{array}$} \\
\hline & $\overline{O R}$ & $95 \% \mathrm{Cl}$ & $\overline{O R}$ & $95 \% \mathrm{Cl}$ & Coef & $95 \% \mathrm{Cl}$ \\
\hline Gender (female vs male) & $0.37^{* * *}$ & $0.23 ; 0.59$ & & & $5.88^{* * *}$ & $5.07 ; 6.68$ \\
\hline Age & & & & & $-0.04^{* *}$ & $-0.08 ;-0.00$ \\
\hline \multicolumn{7}{|l|}{ Education (vs under high school) } \\
\hline Vocational colleges & $1.97^{*}$ & $0.91 ; 4.28$ & $3.56^{* * *}$ & $1.89 ; 6.72$ & & \\
\hline University/postgraduate & $3.01^{* * *}$ & $1.52 ; 5.99$ & & & $1.13^{* * *}$ & $0.29 ; 1.97$ \\
\hline Marital status (living with a partner vs single/divorce/separation) & & & $0.49^{* *}$ & $0.26 ; 0.92$ & & \\
\hline \multicolumn{7}{|l|}{ Employment $^{\mathrm{a}}$ (vs freelancer) } \\
\hline White collar & $3.01^{* * *}$ & $1.70 ; 5.34$ & & & & \\
\hline Blue collar & $2.73^{* *}$ & $1.21 ; 6.16$ & $2.43^{* *}$ & $1.17 ; 5.04$ & & \\
\hline Student & & & 0.39 & $0.12 ; 1.28$ & & \\
\hline Others & 1.86 & $0.85 ; 4.04$ & $0.22^{* *}$ & $0.05 ; 0.97$ & & \\
\hline \multicolumn{7}{|l|}{ Family income $^{\mathrm{b}}$ (vs lowest) } \\
\hline Low & $1.85^{* *}$ & $1.03 ; 3.30$ & & & & \\
\hline Highest & & & & & $-1.24^{* *}$ & $-2.30 ;-0.18$ \\
\hline Area (rural vs urban) & $1.59^{*}$ & $0.93 ; 2.74$ & 0.64 & $0.35 ; 1.20$ & $-1.29^{* * *}$ & $-2.17 ;-0.40$ \\
\hline Have a family member with skin cancer (yes vs no) & $3.57^{*}$ & $0.83 ; 15.36$ & & & & \\
\hline \multicolumn{7}{|l|}{ Source of skin cancer information (yes vs no) } \\
\hline Friends/relatives & $0.40^{* * *}$ & $0.21 ; 0.75$ & & & & \\
\hline Poster/banner & & & 1.78 & $0.83 ; 3.83$ & & \\
\hline Internet & $4.29^{* * *}$ & $2.57 ; 7.16$ & & & & \\
\hline SMS/mobile phone & & & & & $1.49^{* *}$ & $0.20 ; 2.78$ \\
\hline Newspaper/magazine & $1.88^{*}$ & $0.98 ; 3.62$ & 1.73 & $0.84 ; 3.56$ & & \\
\hline Social network & & & & & $2.09^{* * *}$ & $1.07 ; 3.10$ \\
\hline Skin cancer knowledge & 2.16 & $0.78 ; 5.98$ & 2.30 & $0.71 ; 7.53$ & & \\
\hline
\end{tabular}

${ }^{* * *} p<0.01,{ }^{* *} p<0.05,{ }^{*} p<0.1$

${ }^{a}$ Employment: freelancer, people who are self-employed; white collar, office workers; blue collar, manual workers

${ }^{b}$ Family income: we calculated the mean monthly household income of each group

prolonged exposure to the sun [17]. Ozone depletion has caused many problems with skin cancer in the UK, Australia, America, etc. In Australia, melanoma of the skin was one of the third most commonly diagnosed cancers in men and women in 2014 [2]. Although malignant melanoma had a lower incidence rate than nonmelanoma skin cancer, it was still responsible for a sixth of the mortality as a result of cancer among males in Australia [2]. In Vietnam, besides the impact of sun exposure, UV radiation, the transition of the climate, and agent orange, also known as dioxins, are also considered risk factors for skin cancer [18]. However, another study, conducted in a large cohort of Vietnam Army veterans, showed that the impact of dioxin on the non-melanoma skin cancer lesions of patients did not differ between the exposed and unexposed groups [19]. There remains a lack of evidence regarding the most common risk factors for skin cancer in Vietnam, as the majority of the previous studies were conducted in different countries, with different subjects.

Our study revealed that $42.6 \%$ of the respondents use sunscreen; $89.5 \%$ of all respondents used sunscreen coats as a method to prevent skin cancer. These findings show higher sunscreen use than that from the previously published studies; a previous study conducted in Peru found that $38.4 \%$ of the participants used sunscreen daily [13]. Surprisingly, the previous studies conducted in Australia among adolescents showed that only $64 \%$ and $26 \%$ of respondents wore sunscreen and protective clothing, respectively [20]. The differences are reasonable because the target population differed; adolescents infrequently prefer to wear extra clothing as a protection mechanism against the sun. They prefer to wear sunglasses and use sunscreen instead of wearing protective clothing [21]. Interestingly, in our study, men were more knowledgeable and concerned about the risks of skin 
cancer but did not practice any protective behaviors. Conversely, women were more likely to take preventive measures; however, they had fewer concerns about the risks of skin cancer. In Vietnam, women prefer to use a sunscreen coat, which can cover their whole or upper part of the body for cosmetic purpose. Compared to the finding regarding attitudes of sun exposure among outpatients in dermatology clinics in Peru, it was demonstrated that women had more knowledge about sun-protective behavior than men [13].

In this study, all respondents used at least one method to prevent sun exposure when performing outdoor activities. In Vietnam, as a result of urbanization, the motorcycle is the most convenient transportation method for residences. According to the report from the Survey Assessment of Vietnamese Youth 2009 (SAVY2), 95\% of people use motorbikes as their mode of transportation in Vietnam [22]. In Vietnam, to protect themselves from strong sunlight, heat, dust, and risk of accident, most of the biker wear hat/helmet, sunscreen coat/trousers, and sunglasses: this might explain why all respondents use some protection against the sun.

We found that the Internet, social networks, and mobile phones were information sources used by respondents to gain skin cancer knowledge. Previous studies also indicated that the Internet is a vital source of information to provide knowledge about skin cancer [13, 23]. Additionally, previous studies found that the most important sources of information for skin cancer were the television and media, while another study found that the information obtained from the dermatologist and community leader was less important than that from another source [24]. This might be explained because younger people prefer searching for information on the Internet or mass media rather than in dermatological consultation.

Our study may have some implications. The lack of awareness regarding skin cancer may lead to late detections; thus, dermatologists should carefully consult patients regarding melanoma symptoms. Additionally, due to the transition of the climate, as the weather becomes hotter, people might prefer more outdoor activities than they did previously. This may increase the time of exposure to the sun, which may sequentially increase the risk of skin cancer if sun protection methods are not employed. It is necessary to implement interventions that will improve knowledge and raise awareness regarding skin cancer, especially targeting men who exhibited poor protective behaviors. Currently, there is no government-driven, organized skin cancer prevention program to raise awareness on UV protection in Vietnam. The most available source of information on UV protection is commercial advertisements for cosmetic products. As respondents were more likely to search for information about skin cancer on the Internet and mass media, organized skin cancer prevention projects at the government level should take this into account. Health promotion strategies should be developed using these platforms for the entire population.

This study was subject to some limitations that warrant mentioning. Our research used the convenience sampling technique, and the dermatology patients might have more attention towards, and knowledge on, skin cancer prevention, which may limit the generalizability of our findings. Furthermore, selection bias may have occurred because the study was conducted in the National Hospital of Dermatology in Hanoi only. The questionnaire was developed for this study but was not validated. There were some possible biases in our study, including recall bias and social desirability bias, which may pose some limitations regarding the validity of our findings.

\section{Conclusion}

Our study found that the majority of respondents with dermatological issues had basic knowledge regarding skin cancer risks and prevention strategies. Even though men were more knowledgeable and concerned about the risks of skin cancer, they practiced fewer protective behaviors compared to women. Higher education and outdoor occupation were positively associated with increased awareness about skin cancer. Distribution of educational materials, such as brochures in hospitals, aimed at the general population and online health advice provided by health professionals are some of the measures that may be effective in raising awareness.

\footnotetext{
Acknowledgements

We would like to give sincere gratitude to all co-authors for their comments on this paper.
}

Authors' contributions

THTN wrote the first draft of the manuscript including background, methodology, results, discussion, and conclusions. JKO, BXT, CAL, CSHH, and $\mathrm{RCMH}$ provided critical comments and further recommendations for the analysis section. HQP and CTN carried out the statistical analysis and drafted the methodology. SHN and LPD supported the design. The study coordinators were SHN, CSGG, and RCMH. THTN finalized the paper, which was successively read and accepted by co-authors. The author(s) read and approved the final manuscript.

\section{Funding}

The first author, Trang Huyen Thi Nguyen, received funding from the "International Cooperation and Education Program (NCCRI.NCCI 52210-52211, 2018)" of the National Cancer Center, Korea. This work was partially supported by the National Cancer Center Korea under Grant No: 2010303.

Availability of data and materials

The dataset is accessible from the corresponding author upon reasonable request.

Ethics approval and consent to participate

The Institutional Review Board of the Vietnam National Hospital of

Dermatology and Venereology approved the study protocol (code 855/ 
HDDDDBVDLTU). All respondents provided written informed consent to be enrolled.

\section{Competing interests}

None declared.

\section{Author details}

'Department of Cancer Control and Population Health, National Cancer Center Graduate School of Cancer Science and Policy, Goyang, Republic of Korea. ${ }^{2}$ Department of Health Economics, Institute for Preventive Medicine and Public Health, Hanoi Medical University, Hanoi 100000, Vietnam. ${ }^{3}$ Bloomberg School of Public Health, Johns Hopkins University, Baltimore, MD, USA. ${ }^{4}$ National Hospital of Dermatology and Venereology, Hanoi, Vietnam. ${ }^{5}$ Department of Dermatology and Venereology, Hanoi Medical University, Hanoi, Vietnam. ${ }^{6}$ Institute for Global Health Innovations, Duy Tan University, Da Nang, Vietnam. ${ }^{7}$ Faculty of Medicine, Duy Tan University, Da Nang, Vietnam. ${ }^{8}$ Center of Excellence in Health Services and System Research, Nguyen Tat Thanh University, Ho Chi Minh City, Vietnam. ${ }^{9}$ Department of Psychological Medicine, National University Hospital, Singapore, Singapore. ${ }^{10}$ Department of Psychological Medicine, Yong Loo Lin School of Medicine, National University of Singapore, Singapore, Singapore.

${ }^{11}$ Institute for Health Innovation and Technology (iHealthtech), National University of Singapore, Singapore, Singapore.

Received: 11 May 2020 Accepted: 22 July 2020

Published online: 01 August 2020

\section{References}

1. Bray F, Ferlay J, Soerjomataram I, Siegel RL, Torre LA, Jemal A. Global cancer statistics 2018: GLOBOCAN estimates of incidence and mortality worldwide for 36 cancers in 185 countries. CA Cancer J Clin. 2018;68(6):394-424.

2. Australian Institute of Health and Welfare. Cancer in Australia: an overview 2014. Cancer series No 90. Cat. no. CAN 88. Canberra: AlHW.

3. Centers fo Disease Control and Prevention. Unite States Cancer Statistics. U. S. cancer statistics data visualizations tool. In. www.cdc.gov/cancer/dataviz; 2017.

4. Ward WH, Farma JM. Cutaneous melanoma: etiology and therapy. Brisbane (AU): Codon Publications; 2017

5. Erdmann F, Lortet-Tieulent J, Schuz J, Zeeb H, Greinert R, Breitbart EW, et al. International trends in the incidence of malignant melanoma 1953-2008-are recent generations at higher or lower risk? Int J Cancer. 2013;132(2):385400.

6. Apalla Z, Lallas A, Sotiriou E, Lazaridou E, loannides D. Epidemiological trends in skin cancer. Dermatol Pract Concept. 2017;7(2):1-6.

7. Rogers HW, Weinstock MA, Feldman SR, Coldiron BM. Incidence estimate of nonmelanoma skin cancer (keratinocyte carcinomas) in the U.S. population, 2012. JAMA Dermatology. 2015;151(10):1081-6.

8. Gandini S, Sera F, Cattaruzza MS, Pasquini P, Picconi O, Boyle P, et al. Metaanalysis of risk factors for cutaneous melanoma: II. Sun exposure. Eur J Cancer (Oxford, England: 1990). 2005;41(1):45-60.

9. Diffey B. Climate change, ozone depletion and the impact on ultraviolet exposure of human skin. Phys Med Biol. 2004;49(1):R1-11.

10. Cho JM, Davis DMR, Wetter DA, Bartley AC, Brewer JD. Association between atopic dermatitis and squamous cell carcinoma: a case-control study. Int J Dermatol. 2018;57(3):313-6.

11. Jensen A, Sværke C, Farkas D, Olesen A, Kragballe K, Sorensen H. Atopic dermatitis and risk of skin cancer. Am J Clin Dermatol. 2012;13:29-36.

12. Sena JS, Girao RJ, Carvalho SM, Tavares RM, Fonseca FL, Silva PB, et al. Occupational skin cancer: systematic review. Revista da Associacao Medica Brasileira (1992). 2016;62(3):280-6.

13. Thomas-Gavelan E, Saenz-Anduaga E, Ramos W, Sanchez-Saldana L, Sialer MC. Knowledge, attitudes and practices about sun exposure and photoprotection in outpatients attending dermatology clinics at four hospitals in Lima, Peru. An Bras Dermatol. 2011;86(6):1122-8.

14. Ivanov NN, Swan A, Guseman EH, Whipps J, Jensen LL, Beverly EA. Medical students' knowledge, attitudes, and behaviors with regard to skin cancer and sun-protective behaviors. J Am Osteopathic Assoc. 2018;118(7):444-54

15. Jungers EA, Guenthner ST, Farmer ER, Perkins SM. A skin cancer education initiative at a professional baseball game and results of a skin cancer survey. Int J Dermatol. 2003;42(7):524-9.
16. Bharath AK, Turner RJ. Impact of climate change on skin cancer. J R Soc Med. 2009;102(6):215-8.

17. van der Leun JC, de Gruijl FR. Climate change and skin cancer. Photochem Photobiol Sci. 2002;1(5):324-6.

18. Frumkin H. Agent Orange and cancer: an overview for clinicians. CA Cancer J Clin. 2003:53(4):245-55.

19. Nosrati N, Han J, Flores R, Sood R, Tholpady SS. The effect of agent Orange on nonmelanoma skin cancer regression rates. JAMA Surgery. 2014;149(11): 1205-6.

20. Koch S, Pettigrew S, Hollier LP, Slevin T, Strickland M, Minto C, et al. Trends in Australian adolescents' sun-protection behaviours: implications for health campaigns. Aust N Z J Public Health. 2016;40(5):468-73.

21. Makin J. Implications of climate change for skin cancer prevention in Australia. Health promotion journal of Australia: official journal of Australian Association of Health Promotion Professionals 2011, 22 Spec No:S39-41.

22. Le LC, Blum RW. Road traffic injury among young people in Vietnam: evidence from two rounds of national adolescent health surveys, 2004-2009. Glob Health Action. 2013;6:1-9.

23. AlGhamdi KM, AlAklabi AS, AlQahtani AZ. Knowledge, attitudes and practices of the general public toward sun exposure and protection: a national survey in Saudi Arabia. Saudi Pharm J. 2016;24(6):652-7.

24. Wan M, Hu R, Li Y, Wang Y, Xie X, Yue P, et al. Attitudes, beliefs, and measures taken by parents to protect their children from the sun in Guangzhou City, China. Photochem Photobiol. 2016;92(5):753-9.

\section{Publisher's Note}

Springer Nature remains neutral with regard to jurisdictional claims in published maps and institutional affiliations.

Ready to submit your research? Choose BMC and benefit from:

- fast, convenient online submission

- thorough peer review by experienced researchers in your field

- rapid publication on acceptance

- support for research data, including large and complex data types

- gold Open Access which fosters wider collaboration and increased citations

- maximum visibility for your research: over $100 \mathrm{M}$ website views per year

At $\mathrm{BMC}$, research is always in progress.

Learn more biomedcentral.com/submissions 